\title{
Aplikasi Fuzzy Type-2 PSS untuk Perbaikan Stabilitas Dinamik Pembangkit Listrik Tenaga Mikro Hidro dan Diesel
}

\section{Application of Fuzzy Type-2 PSS to Improve Dynamic Stability of Micro Hydro and Diesel Power Plants}

\author{
I.M.A. Nrartha *, I.M. Ginarsa, S. Sultan, A.B. Muljono dan W. Warindi \\ Dept. of. Electrical Eng., Fakultas Teknik, UNRAM, Nusa Tenggara Barat, \\ INDONESIA. Tel. +62-0370 632125, Fax. +62-0370 632125, \\ *corresponding author, email: nrartha@unram.ac.id
}

Manuscript received: 30-10-2021. Accepted: 20-12-2021

\begin{abstract}
ABSTRAK
Teknologi fuzzy tipe 2 (FT2) berkembang sangat pesat dan memasuki bidang stabilitas sistem tenaga listrik. Pembangkit listrik tenaga mikro hidro (PLTMH) dan diesel (PLTD) riskan terhadap gangguan perubahan beban. Studi stabilitas penting dikerjakan untuk memastikan bahwa operasi PLTMH-PLTD tetap stabil ketika dan setelah beban berubah. Maka power system stabilizer (PSS) berbasis FT2 diusulkan untuk perbaikan stabilitas sistem tersebut. FT2PSS didesain dengan input kecepatan rotor dan derivatifnya. Outputnya adalah sinyal stabilitas yang diumpankan pada sistem eksitasi. Hasilnya, FT2PSS mampu mereduksi overshoot $\square 0,035 \mathrm{deg}$. Sedangkan overshoot untuk CPSS adalah $\square 0,051$ deg. FT2PSS juga dapat mempersingkat settling time dan mempercepat steady state. Stabilitas PLTMHPLTD yang dilengkapi dengan FT2PSS diperbaiki secara significan.
\end{abstract}

Kata kunci: Fuzzy tipe 2; PLTMH-PLTD; PSS; perbaikan respons; stabilitas dinamik

\begin{abstract}
Fuzzy tipe 2 (FT2) technology is growing up very fast dan this technology is penetrating into power system stability. Micro hydro (MHPP) and diesel (DPP) power plants are risk to load-changed. Stability study is important to be conducted to ensure that the MHPP-DPP is in stabil operation during and after load-changed. Power system stabilizer (PSS) based on FT2 is proposed to maintain that system. FT2PSS is design with rotor speed and its derivative as inputs. The stability signal ourput is fed to the excitation system. Simulation shows that the overshoot is reduced by the FT2PSS on $\square 0.035 \mathrm{deg}$ for the DPP. Also, proposed PSS makes to shorter settling time and to speed up the steady state. The MHPP-DPP stability is maintained significantly for the system equipped by FT2PSS.
\end{abstract}

Key words: Dinamic stability; fuzzy type 2; MHPP-DPP; PSS; response maintenance 


\section{PENDAHULUAN}

Kemajuan teknologi soft computing makin hari makin berkembang dengan pesat. Soft computing telah memasuki bidang sistem tenaga listrik (STL), khususnya untuk perbaikan stabilitas dinamik menggunakan power system stabilizer (PSS). Sebelumnya, penelitian soft computing untuk STL telah dikerjakan antara lain: Perbaikan stabilitas tegangan dan daya dengan menerapkan adaptive neuro-fuzzy inference system (Muljono et al., 2015; Ginarsa et al., 2014; Ginarsa et al., 2013) dan fuzzy tipe-2 (Ginarsa et al., 2018). Soft computing juga digunakan untuk mereduksi respons transient pada high voltage direct current (Ginarsa et al., 2022; 2020; 2019; 2018). Soft computing jenis fuzzy type-2 untuk desain PSS dan diaplikasikan untuk perbaikan stabilitas STL multi mesin (Sreedivya et al., 2021). Tuning yang optimal PSS fuzzy type-2 berbasis algoritma evolusi diferensial. Algoritma ini mampu memperbaiki osilasi elektro-mekanik sistem multi mesin (Sun et al., 2014). Metode fuzzy adaptif mode sliding digunakan untuk perbaikan stabilitas mesin tunggal dan multi mesin. Stabilitas sistem ini dipastikan baik dengan pengujian Lyapunov analisis dan sintesis (Ray et.al, 2018).

Sementara itu, transfer daya lebih mudah dilakukan dengan beroperasinya unit-unit distributed generation (DG). Transfer daya dengan pertimbangan lama operasi dan kompleksitas daripada integrasi struktur peralatan (llic et al., 1998) yang menyebabkan titik operasi berfluktuasi dan pola aliran daya yang berakibat pada stabilitas STL. Sistem Kelistrikan Lombok (SKL) mempunyai unit-unit pembangkit generator sinkron yang lokasinya tersebar di level distribusi $20 \mathrm{kV}$. Stabilitas dinamis muncul utamanya masalah in-stabilitas inter atau antar area perlu diperhatikan. SKL disuplai oleh PLTD dan PLTMH. PLTMH beropersi sebagai pembangkit cadangan pada musim hujan. Masuknya DG ke sistem akan makin pesat, oleh karenanya perhatian ditujukan dengan pertimbangan efek kumulatif kapasitas level DG yang signifikan pada STL utama. Topik penelitian saat ini lebih banyak menaruh perhatian pada dampak DG terhadap stabilitas sistem. Masalah lain yang relevan antara lain: Dampak penjadwalan pembangkitan terhadap pemenuhan kebutuhan beban nyata, penyediaan daya reaktif, pembangkit cadangan, dan pengasutan awal setelah blackout (Narang, 2006). Pengaruh DG dengan tipe berbeda termasuk generator sinkron pada stabilitas transient dan stabilitas tegangan dilakukan oleh (Slootweg dan Kling, 2002; Nikman et al., 2003) dan DG skala-besar pada stabilitas STL (Narang, 2006). Penelitian stabilitas dan tuning PSS pada STL Jawa-Bali Area IV (Ginarsa, 2001) dan STL Jawa-Bali Area II Soeprijanto (1995). Hasilnya adalah stabilitas STL dapat diperbaiki dengan memasang PSS.

Untuk merespons perubahan beban pada sistem PLTMH-PLTD dan sistem tidak masuk ke mode in-stabilitas. Maka metode fuzzy tipe 2 sangat menjanjikan diaplikasikan untuk desain PSS. Penelitian ini mengusulkan desain PSS dengan metode fuzzy tipe 2 untuk perbaikan stabilitas sistem multi mesin PLTMH-PLTD.

\section{BAHAN DAN METODE}

\section{Alat dan Bahan}

Bahan penelitian ini adalah personal computer (PC) spesifikasi prosesor Intel(R) Core (TM) i5-3570@3.40 GHz, RAM 16 GB, x64-based procesor. Sistem lengkap dengan CDROM, Mouse, dan komponen pendukungnya. Perangkat-lunak yang digunakan adalah Microsoft Windows 10 Profesional, perangkat-lunak MATLAB/Simulink Ver. 2014a sebagai pengolah data dan model stabilitas Sistem Kelistrikan Lombok yang merupakan STL interkoneksi pada level tegangan distribusi $20 \mathrm{kV}$ seperti pada Gambar 1. Sistem ini terdiri dari 1 
unit PLTD $\left(\mathrm{G}_{1}\right), 1$ unit PLTMH $\left(\mathrm{G}_{4}\right), 2$ buah transformator, 1 unit transmisi dan 1 unit bus takhingga (infinite Bus).

\section{Metode}

Pembangunan model stabilitas sinyal-kecil untuk sistem multi mesin hybrid (PLTMHPLTD). Untuk perbaikan stabilitas dinamik model ini maka dilengkapi dengan power system stabilizer (PSS) berbasis fuzzy type-2. Pertama-tama, yang dilakukan adalah membuat dan menjalankan program aliran daya listrik (load flow) untuk memperoleh daya beban dan daya pembangkitan masing-masing unit pembangkit (Kundur, 1984). Langkah berikutnya adalah menyederhanakan model impedansi/admitansi jaringan listrik SKL menjadi model stabilitas sinyal kecil. Hanya bus mesin yang paling kuat koneksinya dengan bus mesin PLTMH (Bus 4) yang diperhitungkan sebagai bus generator (Bus 1). Sementara itu, bus generator yang lain disatukan menjadi bus tak-hingga (infinit-bus). Bus-bus beban dan jaringan-jaringan yang lain direduksi dan dijadikan bus beban dengan beban statik. Berikutnya, membangun model conventional PSS (kompensasi lead-lag, CPSS) untuk dimasukkan ke model sinyal dan CPSS ditala supaya dapat bekerja dengan model tersebut. Kemudian merancang PSS berbasis fuzzy type-2 untuk menggantikan fungsi CPSS. Adapun tujuan dari rancangan PSS berbasis fuzzy type-2 adalah untuk memperbaiki stabilitas dinamik model sinyal kecil mesin hybrid tersebut. Gambar 1 menunjukkan diagram segaris mesin hybrid yang digunakan pada penelitian ini (Muljono dan Nrartha, 2012).

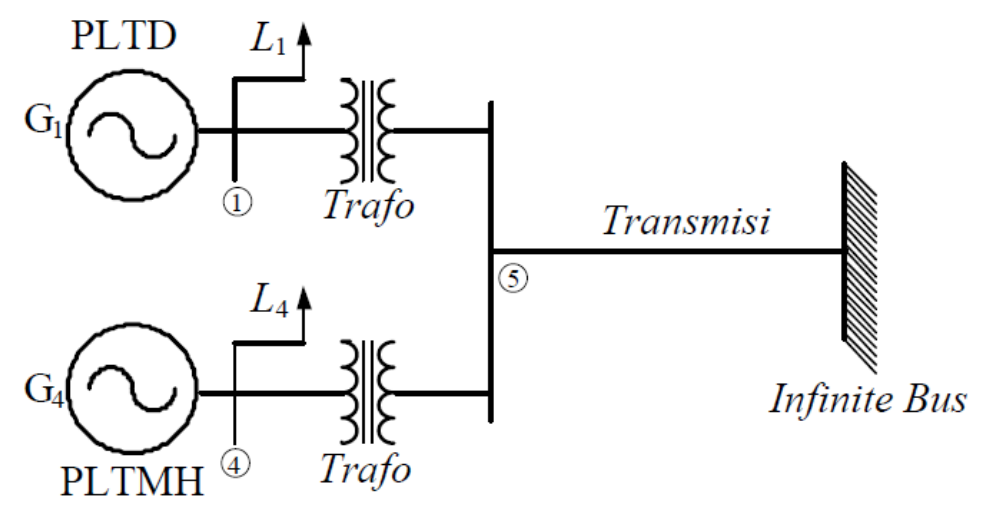

Gambar 1. Model stabilitas sistem tenaga listrik hybrid

\section{Desain Power System Stabilizer (PSS) Model Fuzzy Tipe 2}

Sebelum desain PSS fuzzy, maka dikenalkan dulu conventional PSS (CPSS). Diagram blok CPSS diilustrasikan pada Gambar 2 (a). PSS model fuzzy type-2 dibangun dengan menggunakan algoritma fuzzy tipe Sugeno. Fuzzy tipe 2 didesain menggunakan 2 input yaitu kecepatan rotor $(\Delta \omega)$ dan derivatifnya $(d \Delta \omega)$. Fungsi keanggotaan (membership function, MF) ditentukan dengan setiap input terdiri dari 3 MF. Jenis MF yang digunakan adalah fungsi Gauss MF, masing-masing tiga untuk upper MF dan 3 lower MF. Pamameter Gauss MF ditala dengan metode heuristik. Tiga buah Gauss MF digunakan untuk input kecepatan rotor (input 1) diilustrasikan pada Gambar 2 (b). Untuk output menggunakan MF konstan dengan nilai konstanta: $-1 ;-0,5 ; 0 ; 0,5$ dan 1 . Untuk menghubungkan input dan output maka disusun basis 
aturan terdiri dari 9 aturan seperti pada Gambar 2 (c). Sehingga diperoleh bentuk permukaan kontrol input-output seperti pada Gambar 2 (d).

\section{Tahapan Pengujian dan Validasi}

Tahap berikutnya, pengujian FT2PSS dilakukan dengan sistem SKL yang telah dimodelkan dengan model sinyal kecil. Pengujian PSS model fuzzy tipe 2 dilakukan dengan gangguan kenaikan beban pada Bus PLTD dan Bus PLMTH secara bergilir, yang diimplementasikan dengan sinyal step 6\%. Untuk memvalidasi hasil simulasi dari model sinyal kecil ini dan FT2PSS, maka model ini juga diuji dengan dilengkapi CPSS dan tanpa (no) PSS. Cara pengujian CPSS dan tanpa (no) PSS sama dengan pengujian FT2PSS. Adapun pengujian masing-masing PSS tersebut dapat dibagi menjadi 2 skenario yaitu:

a. Skenario I: Kenaikan beban $6 \%$ pada Bus PLTD.

b. Skenario II: Kenaikan beban 6\% pada Bus PLTMH.

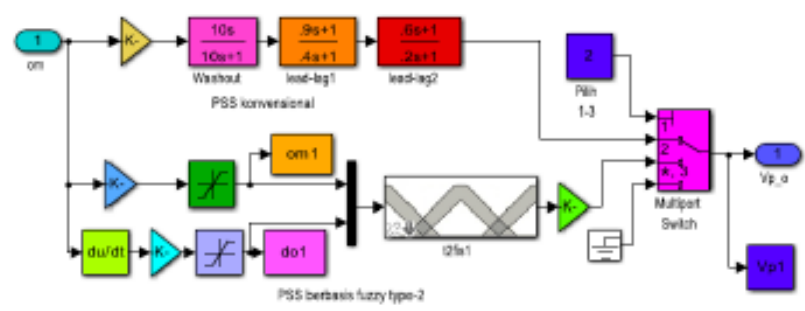

a. PSS konvensional dan PSS fuzzy type-2

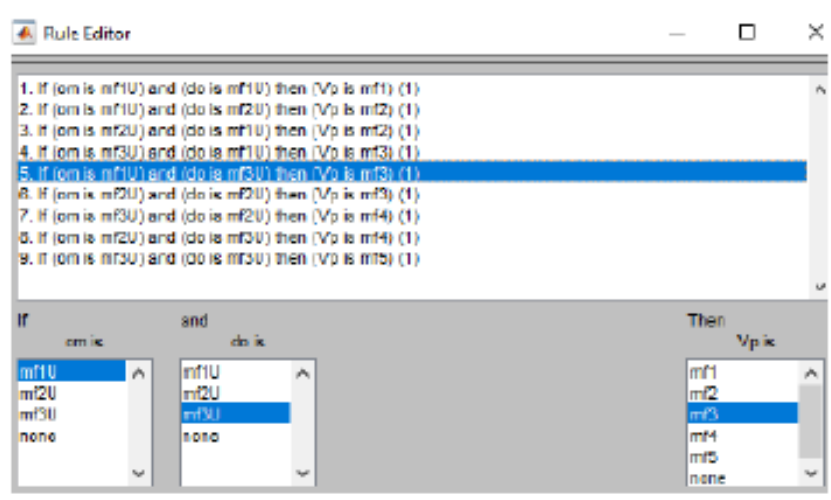

c. Sembilan (9) basis aturan fuzzy

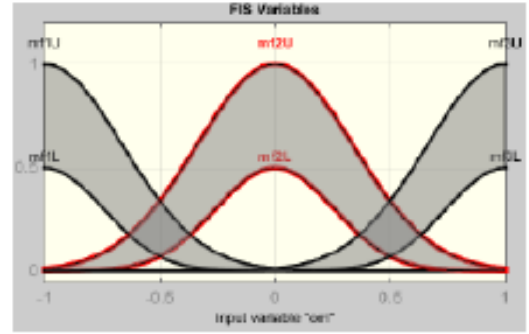

b. Fungsi keanggotaan input kecepatan rotor

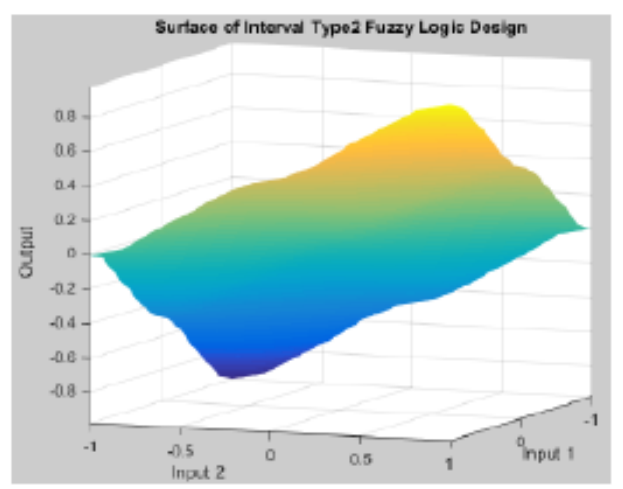

d. Permukaan kontrol PSS type-2

Gambar 2. Desain PSS model fuzzy type-2

\section{HASIL DAN PEMBAHASAN}

Pada Skenario I: Beban di Bus PLTD dinaikkan sebesar 6\% (0,06 pu), respons kecepatan rotor yang dihasilkan oleh masing-masing PSS diilustrasikan pada Gambar 3-4, Tabel 1 dan 2. Gambar 3 (a) dan Tabel 1 diartikan bahwa peak overshoot $\left(M_{p}\right)$ dari FT2PSS adalah lebih kecil $\left(-8,96 \times 10^{-4} \mathrm{rad} / \mathrm{s}\right)$ dibanding dengan CPSS $\left(-13,3 \times 10^{-4} \mathrm{rad} / \mathrm{s}\right)$ dan no PSS $\left(-17,6 \times 10^{-4} \mathrm{rad} / \mathrm{s}\right)$. Settling time $\left(t_{s t}\right)$ dari FT2PSS dicapai pada waktu 1,21 s. Sementara, settling time dari CPSS 
dan no PSS dicapai pada waktu masing-masing 2,78 s dan lebih lama dari 5 s. Pada Gambar 3(b) dan Tabel 1 memperlihatkan bahwa respons dari FT2PSS mampu mereduksi peak overshoot menjadi $-1,08 \times 10^{-4} \mathrm{rad} / \mathrm{s}$. Sedangkan CPSS dan no PSS menghasilkan peak overshoot masing-masing $-1,35 \times 10^{-4} \mathrm{rad} / \mathrm{s}$ dan $-3,34 \times 10^{-4} \mathrm{rad} / \mathrm{s}$. FT2PSS mampu mempercepat steady state dengan waktu $2,93 \mathrm{~s}$. CPSS dan no PSS memberikan steady state pada waktu 3,01 s dan lebih dari $5 \mathrm{~s}$.

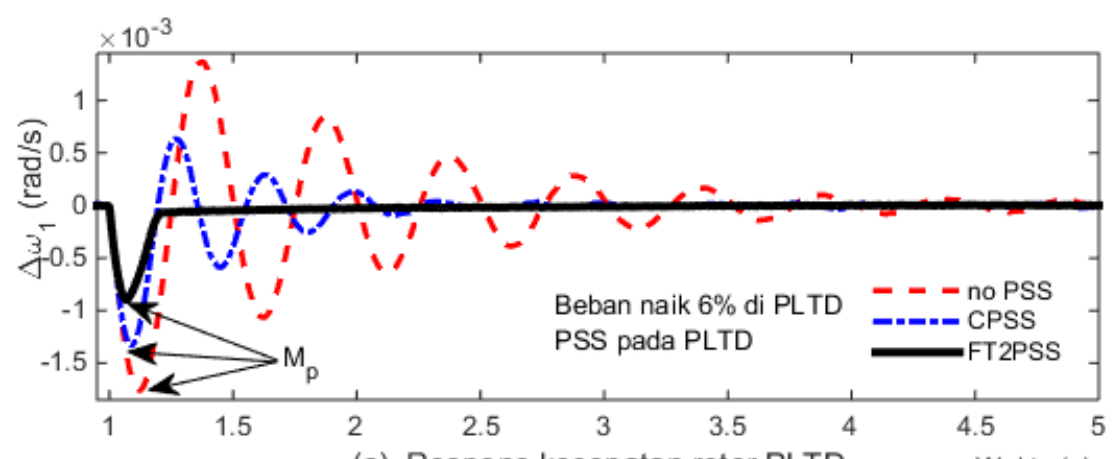

(a). Respons kecepatan rotor PLTD Waktu (s)

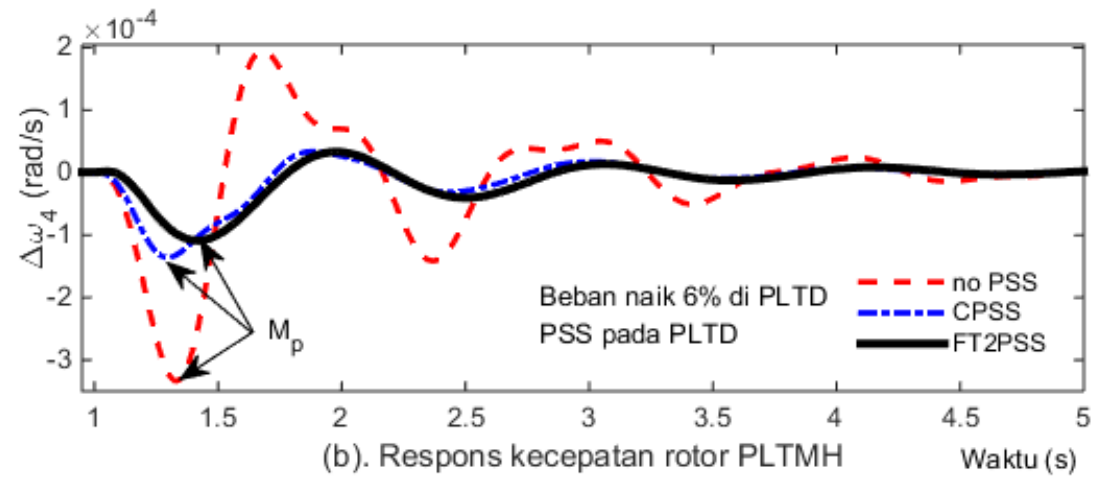

Gambar 3. Perbaikan respons kecepatan rotor PLTD/PLTMH oleh FT2PSS 

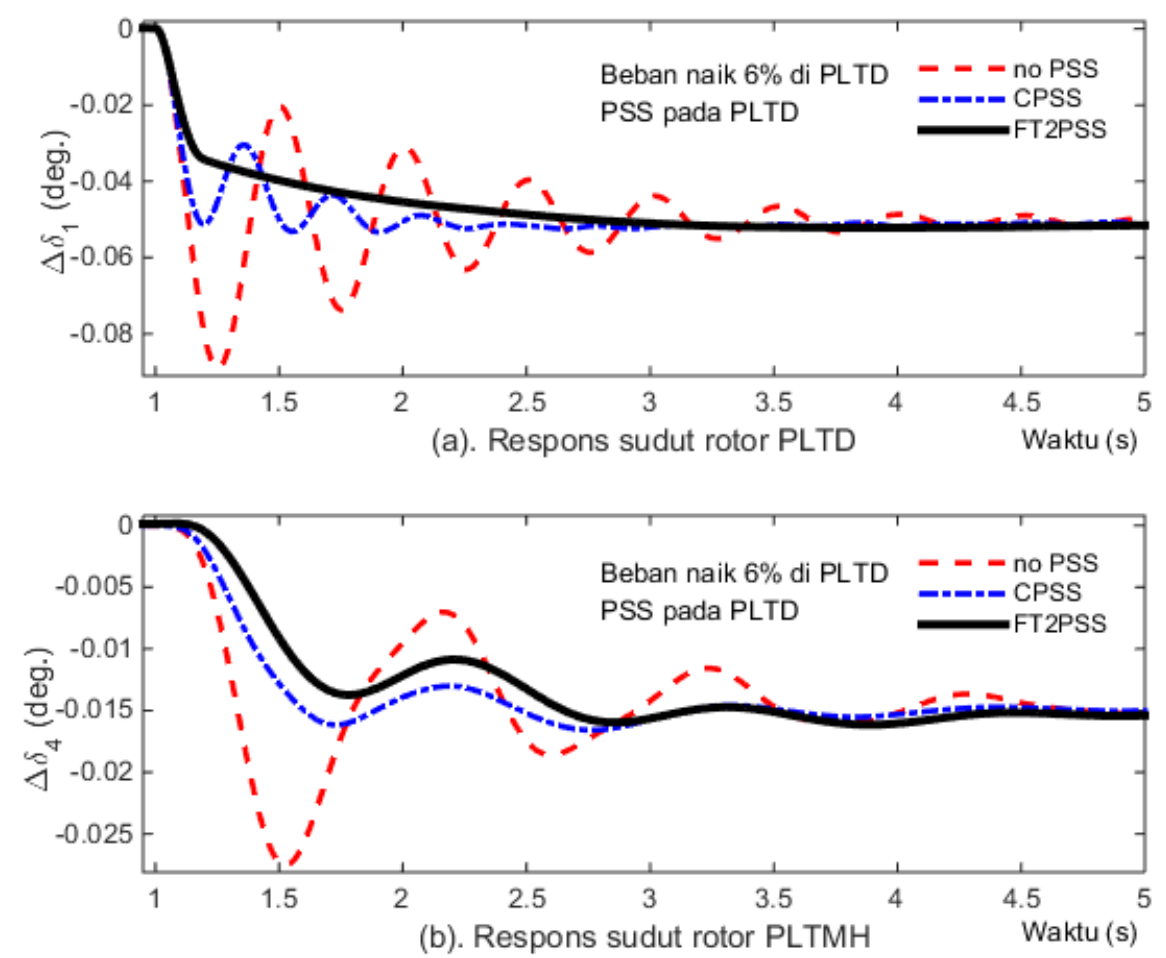

Gambar 4. FT2PSS mampu memperbaiki respons sudut rotor PLTD/PLTMH

Respons sudut rotor PLTD yang dihasilkan oleh kedua PSS ditunjukkan pada Gambar 4 (a) dan Tabel 2. Hasil tersebut memperlihatkan bahwa respons FT2PSS mampu menekan peak overshoot menjadi lebih kecil pada sudut $-0,035^{\circ}$. PSS yang lain memberikan peak overshoot pada sudut $-0,051^{\circ}$ dan $-0,089^{\circ}$ untuk CPSS dan no PSS. Hasil sudut rotor steady state $\left(\delta_{s s}\right)$ untuk semua PSS adalah pada sudut $-0,0515^{\circ}$. Settling time yang dihasilkan oleh FT2PSS adalah pada waktu 3,21 s. Settling time yang dicapai oleh CPSS dan no PSS pada waktu masing-masing 3,25 dan lebih lama dari 5 s. Gambar 4 (b) dan Tabel 2 adalah respons sudut rotor PLTMH untuk kenaikan beban 6\% di Bus PLTD. Diperoleh juga FT2PSS mampu meredam peak overshoot menjadi $-0,0137^{\circ}$. PSS pembanding menghasilkan peak overshoot $-0,0161^{\circ}$ dan $-0,0276^{\circ}$ untuk CPSS dan no PSS. Juga, respons sudut rotor oleh FT2PSS lebih cepat mencapai steady state daripada CPSS dan no PSS. Nilai steady state untuk semua PSS adalah $-0,0175^{\circ}$.

Tabel 1. Perbaikan respons kec. rotor oleh FT2PSS untuk beban naik 6\%

\begin{tabular}{ccccccc}
\hline $\begin{array}{c}\text { Kecepatan } \\
\text { rotor }(\Delta \omega)\end{array}$ & \multicolumn{2}{c}{ No PSS } & \multicolumn{2}{c}{ CPSS } & \multicolumn{2}{c}{ FT2PSS } \\
\cline { 2 - 7 } & $\begin{array}{c}\boldsymbol{M}_{\boldsymbol{p}} \times\left(-\mathbf{1 0}^{-\mathbf{4}}\right) \\
(\mathbf{r a d} / \mathbf{s})\end{array}$ & $\begin{array}{c}\boldsymbol{t}_{\boldsymbol{s t}} \\
(\mathbf{s})\end{array}$ & $\begin{array}{c}\boldsymbol{M}_{\boldsymbol{p}} \times\left(-\mathbf{- 1 0}^{-4}\right) \\
(\mathbf{r a d} / \mathbf{s})\end{array}$ & $\begin{array}{c}\boldsymbol{t}_{\boldsymbol{s t}} \\
(\mathbf{s})\end{array}$ & $\begin{array}{c}\boldsymbol{M}_{\boldsymbol{p}} \times\left(-\mathbf{1 0}^{-\mathbf{4}}\right) \\
(\mathbf{r a d} / \mathbf{s})\end{array}$ & $\begin{array}{c}\boldsymbol{t}_{\text {st }} \\
(\mathbf{s})\end{array}$ \\
\hline PLTD & 17,6 & $>5$ & 13,3 & 2,78 & 8,96 & 1,21 \\
PLTMH & 3,34 & $>5$ & 1,35 & 3,01 & 1,08 & 2,93 \\
\hline
\end{tabular}

Tabel 2. Unjuk kerja FT2PSS pada beban naik $6 \%$ untuk sudut rotor 


\begin{tabular}{|c|c|c|c|c|c|c|c|c|c|}
\hline \multirow{2}{*}{$\begin{array}{c}\text { Sudut } \\
\text { rotor } \\
(\Delta \delta) \\
\end{array}$} & \multicolumn{3}{|c|}{\begin{tabular}{|l} 
No PSS \\
\end{tabular}} & \multicolumn{3}{|c|}{ CPSS } & \multicolumn{3}{|c|}{ FT2PSS } \\
\hline & $\begin{array}{c}M_{p} \times(-1) \\
\left({ }^{\circ}\right)\end{array}$ & $\begin{array}{l}t_{s t} \\
(\mathbf{s})\end{array}$ & $\begin{array}{c}\delta_{s s} \times(-1) \\
\left({ }^{\circ}\right)\end{array}$ & $\begin{array}{c}M_{p} \times(-1) \\
\left({ }^{\circ}\right)\end{array}$ & $\begin{array}{l}t_{s t} \\
(\mathbf{s})\end{array}$ & $\begin{array}{c}\delta_{s s} \times(-1) \\
\left({ }^{\circ}\right)\end{array}$ & $\begin{array}{c}M_{p} \times(-1) \\
\left({ }^{\circ}\right)\end{array}$ & $\begin{array}{l}t_{s t} \\
(\mathbf{s})\end{array}$ & $\begin{array}{c}\delta_{s s} \times(-1) \\
\left({ }^{\circ}\right)\end{array}$ \\
\hline PLTD & 0,089 & $>5$ & 0,0515 & 0,051 & 3,25 & 0,0515 & 0,035 & 3,21 & 0,0515 \\
\hline PLTMH & 0,0276 & $>5$ & 0,0175 & 0,0161 & 3,95 & 0,0175 & 0,0137 & 3,52 & 0,0175 \\
\hline
\end{tabular}

\section{Perbaikan Respons Ketika Beban Naik 6\% pada Bus PLTMH}

Skenario II: Gangguan berupa kenaikan beban sebesar 6\% pada Bus PLTMH. Respons kecepatan rotor semua PSS diwujudkan pada Gambar 5 (a) dan 5 (b), dan parameternya diurutkan pada Tabel 3 dan 4 . Hasil simulasi menunjukkan bahwa FT2PSS mampu mereduksi peak overshoot kecepatan rotor menjadi $-0,52 \times 10^{-4} \mathrm{rad} / \mathrm{s}$. Hasil dari CPSS dan no PSS adalah masing-masing sebesar $-1,64$ dan $-2,93 \times 10^{-4} \mathrm{rad} / \mathrm{s}$. Steady state yang dicapai oleh FT2PSS adalah pada waktu 3,26 s untuk kecepatan rotor. Disisi lain, CPSS dan no PSS menghasilkan steady state pada masing-masing 4,03 dan lebih lama dari $5 \mathrm{~s}$. Hasil simulasi kenaikan beban 6\% pada PLTMH dapat dilihat pada Gambar 5 (b) dan Tabel 3. Hasil tersebut menunjukkan respons kecepatan dan sudut rotor PLTMH tidak dipengaruhi oleh pemasangan PSS di PLTD.
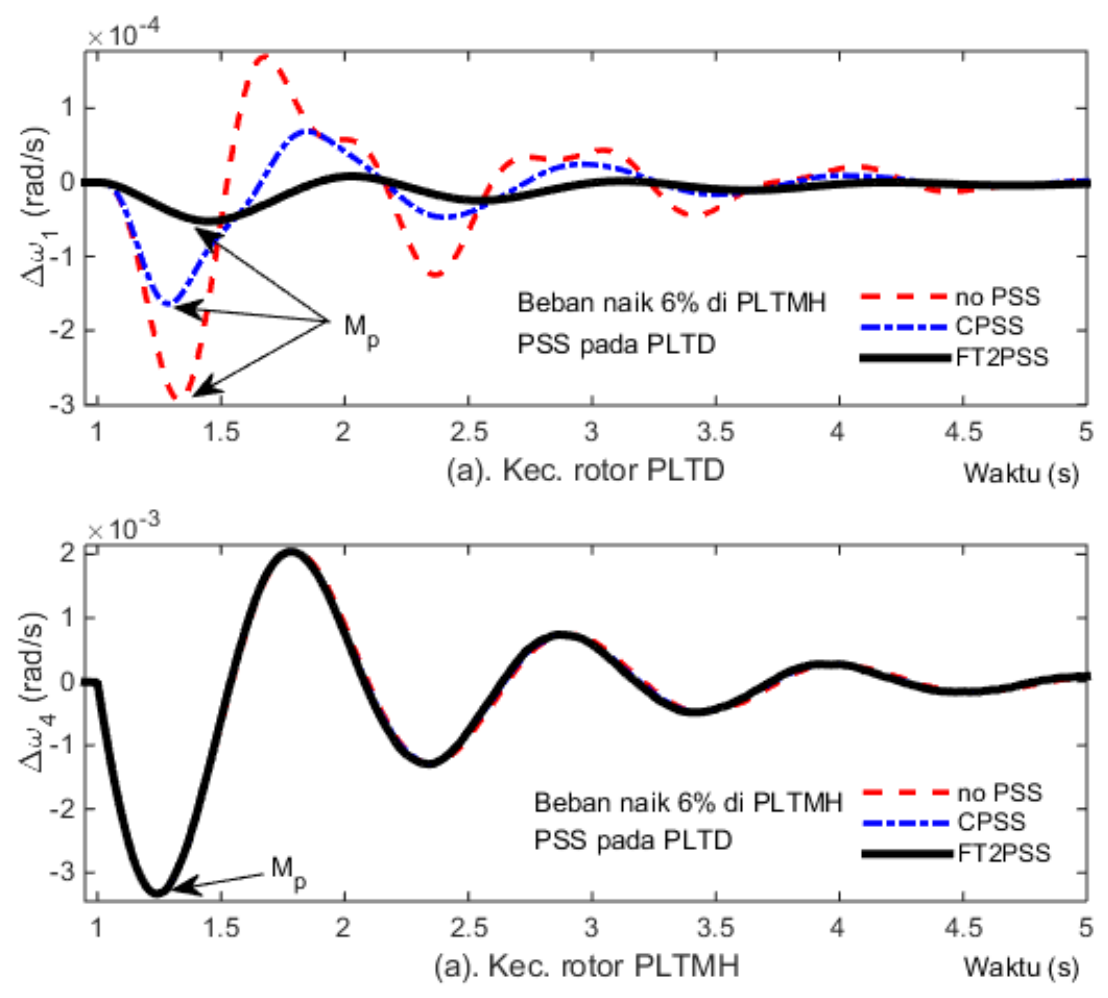

Gambar 5. Kecepatan rotor karena kenaikan beban 6\% pada Bus PLTMH 


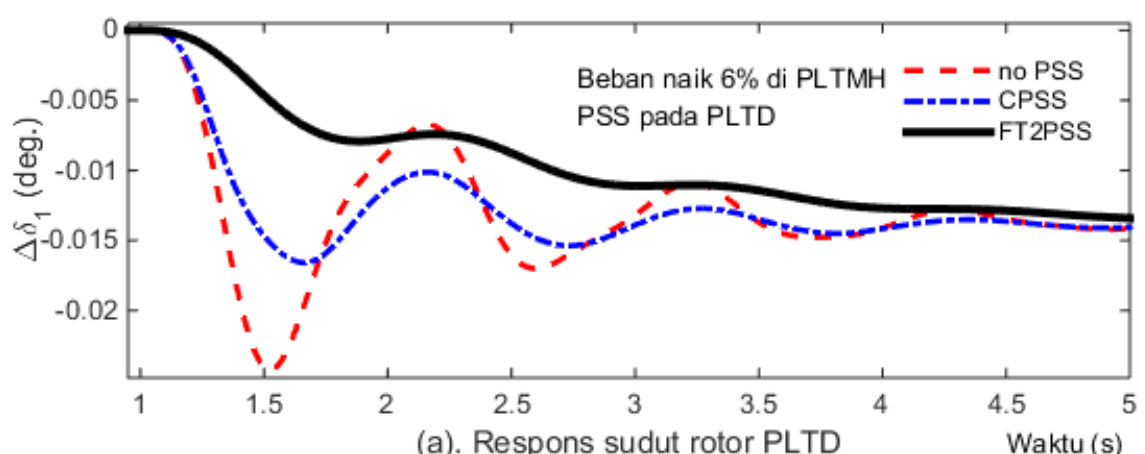

(a). Respons sudut rotor PLTD

Waktu (s)

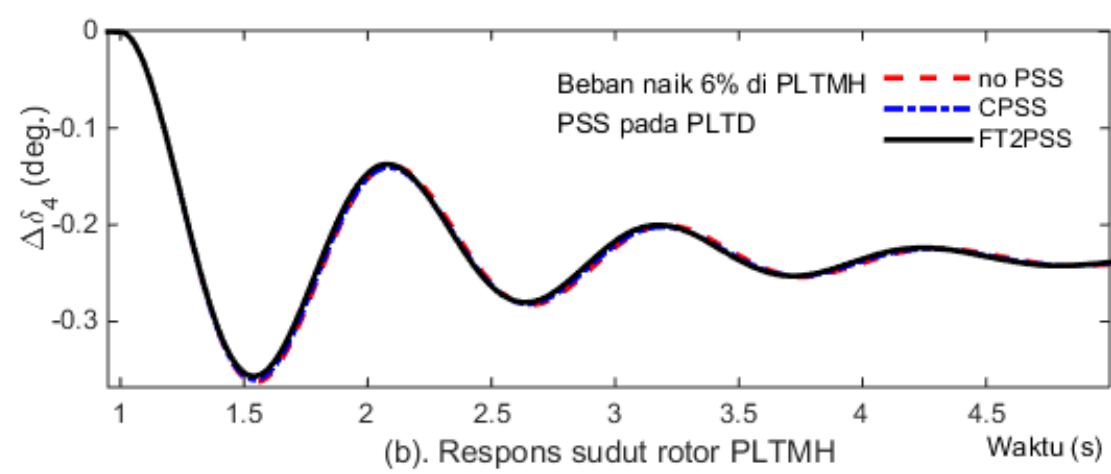

Gambar 6. Sudut rotor akibat gangguan beban 6\% di Bus PLTMH

Respons sudut rotor diilustrasikan pada Gambar 6(a) dan Tabel 4, untuk gangguan beban naik 6\% pada Bus PLTMH. Hasil ini menunjukkan bahwa peak overshoot dari FT2PSS diperoleh sebesar $-0,0078^{\circ}$. Hasil untuk CPSS dan no PSS adalah masing-masing $-0,0165$ dan $-0,0242^{\circ}$. Sudut rotor mencapai steady state pada nilai $-0,0145^{\circ}$ untuk semua PSS. FT2PSS menghasilkan settling time pada waktu 3,21 s. PSS yang lain mencapai settling time pada waktu 3,25 s dan lebih lama dari $5 \mathrm{~s}$, untuk CPSS dan no PSS. Hasil simulasi gangguan beban naik di Bus PLTMH dapat digambarkan pada Gambar 6 (b) dan Tabel 4. Diperoleh bahwa aksi PSS di PLTD tidak dapat mereduksi respons sudut rotor PLTMH sehingga berosilasi dengan magnitude lebih besar dari $-0,35^{\circ}$. Sudut rotor ini berosilasi lebih lama dari $5 \mathrm{~s}$ sebelum steady state dicapai. Hasil-hasil simulasi menunjukkan bahwa kecepatan dan sudut rotor bernilai negatif. Hal ini menunjukkan bahwa ketika beban ditambahkan pada bus beban mengakibatkan kecepatan rotor mengalami perlambatan dan sudut rotor semakin tertinggal dari kecepatan sinkron.

Tabel 3. Unjuk kerja FT2PSS saat beban naik 6\% di Bus PLTMH

\begin{tabular}{ccccccc}
\hline $\begin{array}{l}\text { Kecepatan } \\
\text { rotor }(\Delta \omega)\end{array}$ & \multicolumn{2}{c}{ No PSS } & \multicolumn{2}{c}{ CPSS } & \multicolumn{2}{c}{ FT2PSS } \\
\cline { 2 - 7 } & $\begin{array}{c}\boldsymbol{M}_{p} \times\left(-\mathbf{1 0}^{-\mathbf{4}}\right) \\
(\mathbf{r a d} / \mathbf{s})\end{array}$ & $\begin{array}{c}\boldsymbol{t}_{\text {st }} \\
(\mathbf{s})\end{array}$ & $\begin{array}{c}\boldsymbol{M}_{p} \times\left(-\mathbf{- 1 0}^{-\mathbf{4}}\right) \\
(\mathbf{r a d} / \mathbf{s})\end{array}$ & $\begin{array}{c}\boldsymbol{t}_{\text {st }} \\
(\mathbf{s})\end{array}$ & $\begin{array}{c}\boldsymbol{M}_{\boldsymbol{p}} \times\left(-\mathbf{- 1 0}^{-\mathbf{4}}\right) \\
(\mathbf{r a d} / \mathbf{s})\end{array}$ & $\begin{array}{c}\boldsymbol{t}_{\text {st }} \\
(\mathbf{s})\end{array}$ \\
\hline PLTD & 2,93 & $>5$ & 1,64 & 4,03 & 0,52 & 3,26 \\
PLTMH & 33,5 & $>5$ & 33,4 & $>5$ & 33,3 & $>5$ \\
\hline
\end{tabular}


Tabel 4. Respons sudut rotor oleh FT2PSS untuk beban naik $6 \%$ di Bus PLTMH

\begin{tabular}{|c|c|c|c|c|c|c|c|c|c|}
\hline \multirow{2}{*}{$\begin{array}{l}\text { Sudut } \\
\text { rotor } \\
(\Delta \delta)\end{array}$} & \multicolumn{3}{|c|}{ No PSS } & \multicolumn{3}{|c|}{ CPSS } & \multicolumn{3}{|c|}{ FT2PSS } \\
\hline & $\begin{array}{c}M_{p} \times(-1) \\
\left({ }^{\circ}\right)\end{array}$ & $\begin{array}{l}t_{s t} \\
(\mathbf{s})\end{array}$ & $\begin{array}{c}\delta_{s s} \times(-1) \\
\left({ }^{\circ}\right)\end{array}$ & $\begin{array}{c}M_{p} \times(-1) \\
\left({ }^{\circ}\right)\end{array}$ & $\begin{array}{l}t_{s t} \\
(\mathbf{s})\end{array}$ & $\begin{array}{c}\delta_{s s} \times(-1) \\
\left({ }^{\circ}\right)\end{array}$ & $\begin{array}{c}M_{p} \times(-1) \\
\left({ }^{\circ}\right)\end{array}$ & $\begin{array}{l}t_{s t} \\
(\mathbf{s})\end{array}$ & $\begin{array}{c}\delta_{s s} \times(-1) \\
\left({ }^{\circ}\right)\end{array}$ \\
\hline PLTD & 0,0242 & $>5$ & 0,0145 & 0,0165 & 3,25 & 0,0145 & 0,0078 & 3,21 & 0,0145 \\
\hline PLTMH & 0,363 & $>5$ & 0,214 & 0,36 & 3,95 & 0,214 & 0,0356 & 3,53 & 0,214 \\
\hline
\end{tabular}

\section{KESIMPULAN}

Studi stabilitas pada sistem PLTMH-PLTD sangat diperlukan untuk antisipasi perubahan beban dan mencegah sistem ke mode in-stabil. Oleh karena itu, PSS metode fuzzy tipe 2 (FT2PSS) sangat penting dikerjakan untuk memperbaiki stabilitas sistem PLTMH-PLTD. FT2PSS ini didesain dengan 2 input (kecepatan rotor dan derivatifnya) dan satu output (sinyal stabilitas) yang diumpankan ke sistem eksitasi PLTD. Membership function (MF) untuk input disusun dengan masing 3 MF lower dan 3 MF upper. Untuk MF output menggunakan konstanta dan untuk menghubungkan inpu-output maka digunakan 9 basis aturan. Hasil simulasi menunjukkan bahwa FT2PSS memberikan perbaikan stabilitas dengan peak overshoot sebesar $-8,96 \times 10^{-4} \mathrm{rad} / \mathrm{s}$ dan $-0,035^{\circ}$ untuk kecepatan dan sudut rotor. Sedangkan CPSS menghasilkan peak overshoot sebesar $-13,3 \times 10^{-4} \mathrm{rad} / \mathrm{s}$ dan $-0,051^{\circ}$. Diperoleh juga, bahwa settling time FT2PSS lebih cepat daripada settling time CPSS. Untuk penelitian selanjutnya, direkomendasikan menggunakan teknik optimasi untuk memperbaiki unjuk kerja FT2PSS dan memperpendek settling time.

\section{Ucapan Terimakasih}

Ucapan terima kasih para penulis sampaikan kepada Kemendikbud/B-RIN atas dukungan pendanaan Penelitian PNBP pembiayaan BLU Universitas Mataram Tahun 2021.

\section{DAFTAR PUSTAKA}

Ginarsa, I.M., et al., 2022. Additional control based on ANFIS algorithm to improve transient current of converter-side in HVDC transmission system. In: Thakkar, F., Procs. of the Int. Conf. E-ISSP 2020, India, Springer Nature: 383-390.

Ginarsa, I.M., et al., 2020. Transient response improvement of direct current using supplementary control based on ANFIS for rectifier in HVDC. IJPEDS Journal. 11(4): 2107-2115.

Ginarsa, I.M., et al., 2019. Simulation of ANFIS controller to line commutation based on current source converter in high voltage direct current. Procs. of CENCON, Yogyakarta. 16-17 Oct.

Ginarsa, I.M., et al, 2018, Desain power system stabilizer berbasis fuzzy tipe-2 untuk perbaikan stabilitas mesin tunggal. Jurnal Rekayasa Elektrika. 14(1): 1-8.

Ginarsa, I.M., et al., 2018. ANFIS-based controller to regulate firing angle of inverter in average value model-high voltage direct current transmission system. Procs. of ICGTEIS, Bali: 1-6.

Ginarsa, I.M. dan Zebua, O., 2014, ’Stability improvement of single machine using ANFISPSS based on feedback-linearization. Telkomnika Journal. 12(2): 315-324. 
Ginarsa, I.M., Soeprijanto, A., Purnomo, M.H., 2013. Controlling chaos and voltage collapse using an ANFIS-based composite controller-static var compensator (CC-SVC) in power systems. IJEPES Journal. vol. 46, pp. 79-88.

Ginarsa, I.M., 2001, Analisis respon frekuensi untuk penalaan power sistem stabilizer pada sistem multimesin. Tesis UGM. Yogyakarta.

Kundur, P., 1984. Power systems stability and control. McGraw-Hill, Inc.

llic, M., Galiana, F., dan Fink, L., 1998. Power systems restructuring. Kluwer Academic Publishers.

Muljono, A.B., Ginarsa, I.M. dan Nrartha, I.M.A., 2015. Dynamic stability improvement of multimachine power systems using ANFIS-based power system stabilizer. Telkomnika 13(4): 1170-1178.

Muljono, A.B. dan Nrartha, I. M. A., 2012. Analisis pengaruh unit pembangkit tersebar terhadap stabilitas dinamis sistem tenaga. Majalah Ilmiah Teknologi Elektro. 8(1): $52-57$.

Narang, A., 2006. Impact of large-scale distributed generation penetration on power system stability. CANMET Energy Technology Centre, Canada.

Nikman, T,. Ranjbar, A.H. dan Shirani, A.R., 2003. Impact of distributed generation on volt/var control in distribution networks. IEEE Bologna Power Tech Conference.

Sreedivya, K.M., Jeyanthy, P.A., Devaraj, D., 2021. Improved design of interval type-2 fuzzy based wide area power system stabilizer for inter-area oscillation damping. Microprocessors and Microsystems, 83: 103957, Elsevier.

Slootweg, J.G. dan Kling, W.L., 2002. Impacts of Distributed Generation on Power System Transient Stability. Power Engineering Society Summer Meeting, 2: 862-867.

Soeprijanto, A., 1995. Metoda sederhana penalaan power system stabilizer. Tesis ITB, Bandung.

Sun, Z., Wang, N., Srinivasan, D., Bi, Y., 2014. Optimal tunning of type-2 fuzzy logic power system stabilizer based on diffrential evolution algorithm. IJEPES, 62: 19-28, Elsevier.

Ray, P.K., Paital, S.R., Mohanty, A., Eddy, F.Y.S., Gooi, H.B., 2018. A robust power system stabilizer for enhancement of stability in power system using adaptive fuzzy sliding mode control Applied Soft Computing Journal, 73: 471-481, Elsevier. 